\title{
The Hakka Cookbook
}




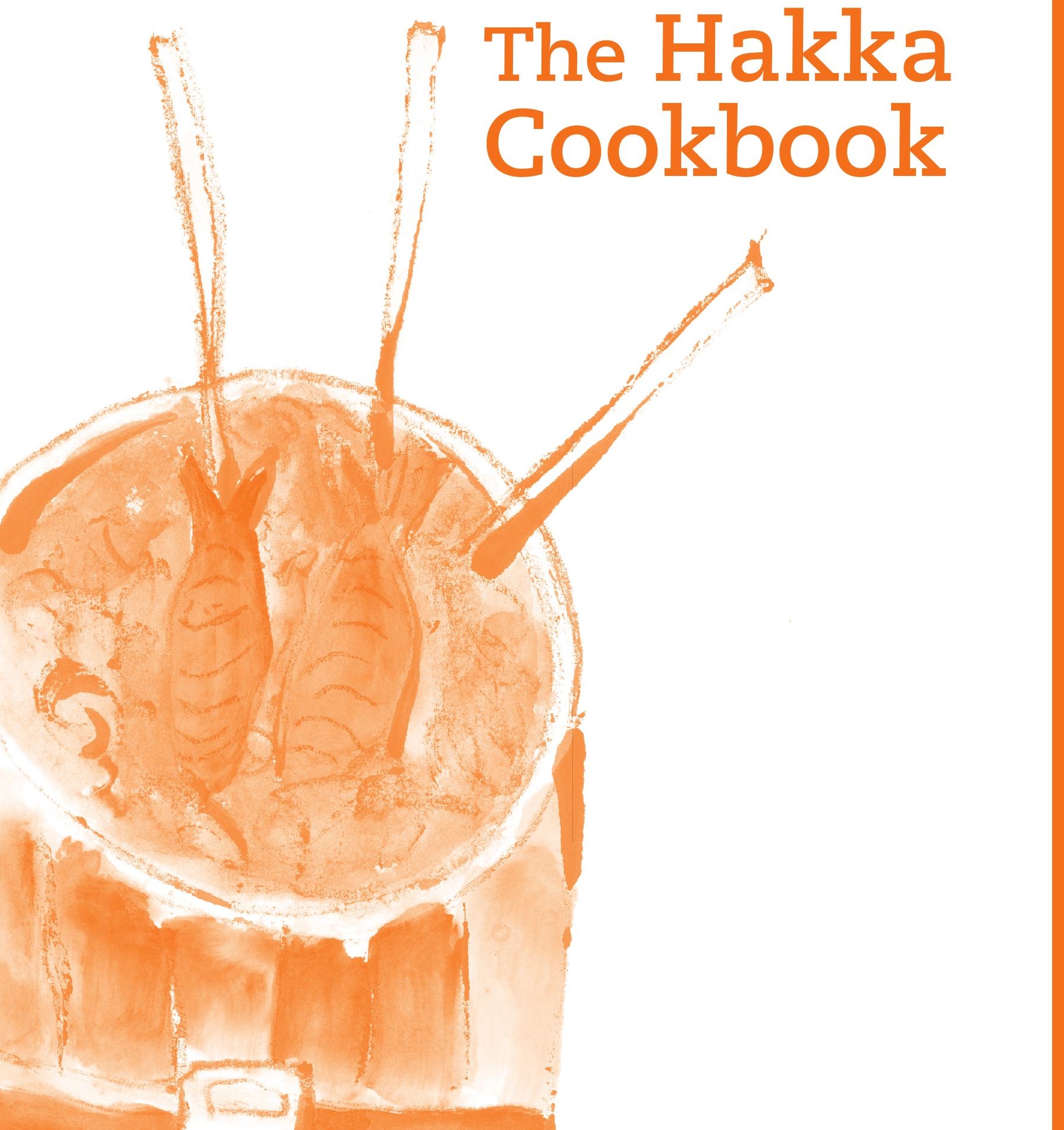




\section{Chinese Soul Food from around the World}

Linda Lau Anusasananan

Art by Alan Lau

Foreword by Martin Yan

甲

UNIVERSITY OF CALIFORNIA PRESS Berkeley Los Angeles London 
The publisher gratefully acknowledges the generous support

of the Sue Tsao Endowment Fund in Chinese Studies

of the University of California Press Foundation.

University of California Press, one of the most distinguished university presses in the United States, enriches lives around the world by advancing scholarship in the humanities, social sciences, and natural sciences. Its activities are supported by the UC Press Foundation and by philanthropic contributions from individuals and institutions. For more information, visit www.ucpress.edu.

University of California Press

Berkeley and Los Angeles, California

University of California Press, Ltd.

London, England

(C) 2012 by Linda Lau Anusasananan

Art $\odot$ Alan Lau

Cover calligraphy @ Chitfu Yu

"the upside down basket" by Alan Chong Lau was previously published in Songs for Jadina

(Greenfield Center, N.Y.: Greenfield Review Press, 1980) and is reprinted with permission.

Design and composition: Claudia Smelser

Text: Adobe Chaparral Pro

Display: PMN Caecilia

Index: Kevin Millham

Prepress and color: iocolor

Printing and binding: Imago

LIBRARY OF CONGRESS CATALOGING-IN-PUBLICATION DATA

Anusasananan, Linda Lau, 1947-

The Hakka cookbook : Chinese soul food from around the world / Linda Lau Anusasananan ; art by Alan Lau; foreword by Martin Yan.

p. $\mathrm{cm}$.

Includes bibliographical references and index.

ISBN 978-0-520-27328-3 (cloth : alk. paper)

1. Cooking, Chinese-Hakka style. 2. Hakka (Chinese people). 3. Chinese diaspora.

I. Title.

TX724.5.C5A64 2012

$641.5951-\mathrm{dc} 23$

2012003052

Manufactured in China

$\begin{array}{llllllllll}21 & 20 & 19 & 18 & 17 & 16 & 15 & 14 & 13 & 12 \\ 10 & 9 & 8 & 7 & 6 & 5 & 4 & 3 & 2 & 1\end{array}$

The paper used in this publication meets the minimum requirements of ANSI/NISO Z39.481992 (R 2002) (Permanence of Paper). 
For Popo, who inspired me to discover what it means to be Hakka.

And for my daughters, Chalida and Lisa, and their children, who inspire me to pass on our history through word and food.

Most of all, this is for Hakkas throughout the world, so they can honor and preserve their roots with the foods of their ancestors. 


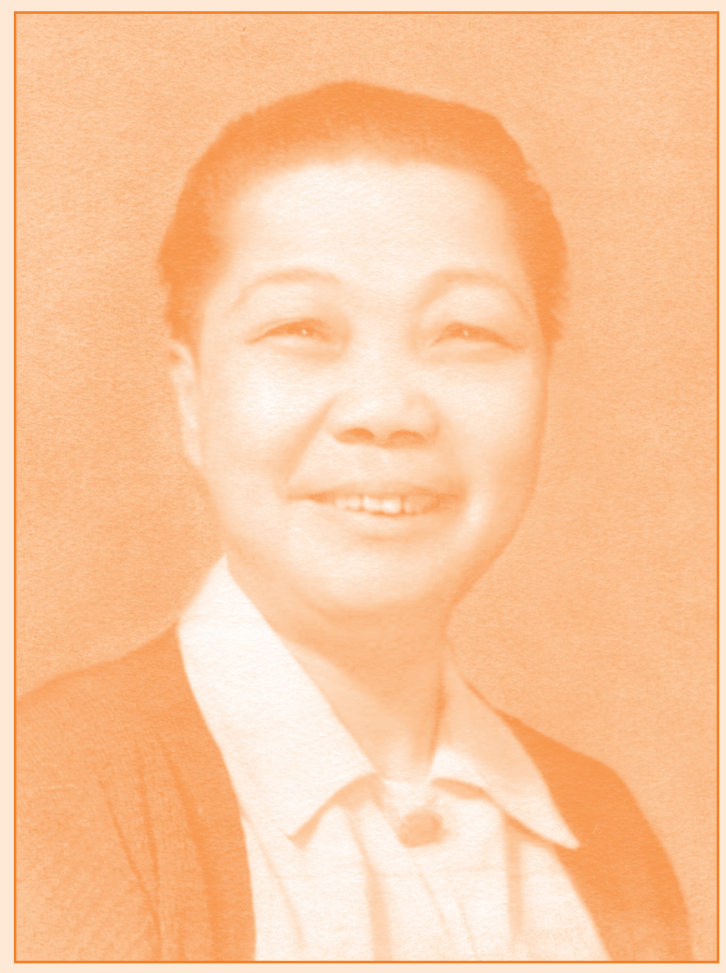

Popo 


\section{the upside down basket}

my grandmother

rakes up chicken shit

mixed with mud

to feed her roses

head protected

by an upside down basket

dares the sun to get closer

her shirt ablaze

with hawaiian pineapples

she imitates the cackle of hens

as they run merry off nests

wings flapping dust

an egg

still warm

cuddles the round

of my chin

a tickle unbearable

so i laugh

and she does too

so hard

the upside down

basket trembles

as though shaking

a fist

at the heat

we walk home

the musk of rotten apples everywhere

incense curling into skin

on the porch the upside down basket

sits rightside up

we drink gallons

of lemonade

Alan Chong Lau 


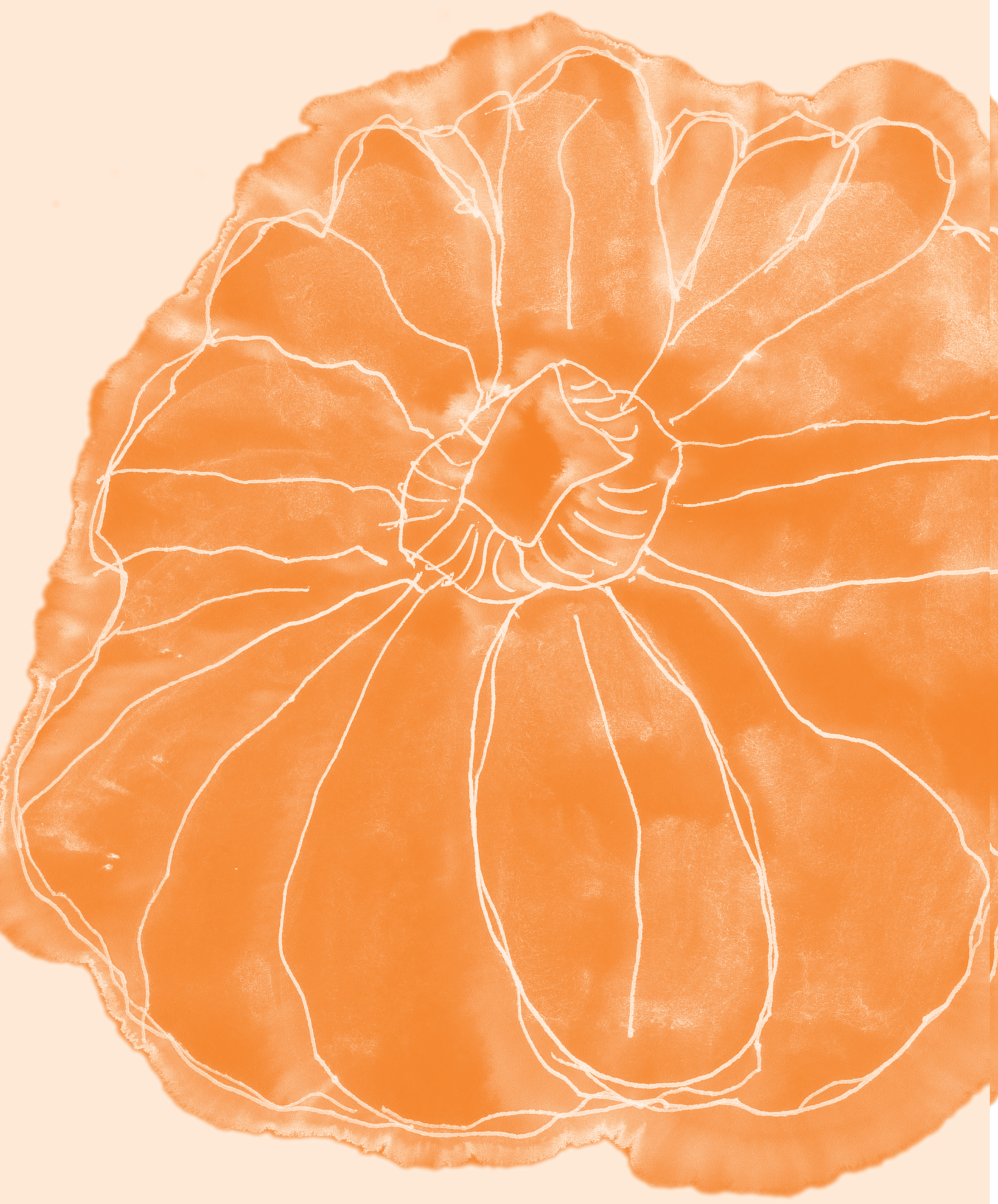

